\title{
THE METHOD OF GLOBAL READING FROM AN INTERDISCIPLINARY PERSPECTIVE
}

Dr. Jasmina Delcheva Dizdarevikj, University St. Cyril and Methodius,
Faculty of Philosophy, Skopje, Macedonia
E-mail: jdelceva@yahoo.com

education,

(C) 2018 IJCRSEE. All rights reserved.

\section{INTRODUCTION}

In the past decade the Macedonian education in general and particularly the Macedonian language classes including the initial literacy have fallen into a continuous and worrying recourse. This is not a speculative note, but an assertion that is backed up by the theoretical knowledge of didactics and methodology and the empirical data obtained from research by relevant institutions. Let's begin with the theory.

As early as the symposium that took place in Ohrid in 2011, titled Education Between The Traditional and the Modern was pointed out that there are serious problems in the objectives stipulated in the curriculum for first and second grade Macedonian language

Corresponding Author

Dr. Jasmina Delcheva Dizdarevikj, University St. Cyril and Methodius, Skopje, Macedonia

E-mail: jdelceva@yahoo.com

This work is licensed under a Creative Commons Attribution - NonCommercial - NoDerivs 4.0. The article is published with Open Access at www.ijcrsee.com in the primary education, as well as a notable discrepancy between those objectives and their compatibility with the text-books.

Demanding knowledge and skills which the students are not developmentally capable to fulfill at such an early state in their education, disrespecting the basic didactic principles in relation to the ratio illustration-text in the textbooks, as well as some methodical inconsistencies in the curriculum, for example "distinguishing the capital and the lowercase letters", although there are only 3 letters in the Macedonian language which have an apparent difference (A-a, Б-б, E-e). It is exceptionally important to emphasize the decision for reestablishment of the parallel teaching of writing in block and cursive letters (a concept abandoned in the 60's because of its inefficiency) which is especially theoretically unsustainable. We can end this infamous streak with one last note: certain goals from the second grade Macedonian language curriculum are only a repetition from the first grade goals. Having said that, the educational continuity is stopped and regression occurs (Delcheva 2013, 181-185).

These are some of the theoretical notes; now we can point out concrete empirical data. 
During 2016 the Step by step foundation conducted research for evaluation of reading and mathematics (EGRA and EGMA). Here are the results of the reading research, which we will quote entirely:

"At a national level, the students have good results in recognizing and accurate pronunciation of the letters, but the skills needed for fluid reading of a short text and its understanding are not well-developed, regardless of the language of instruction. The understanding of the read text is a great challenge for the second and third graders. The results show that the students cannot achieve the international standard to be able to answer $80 \%$ of the asked questions, in any language of instruction. Longitudinally, the fluent reading and the understanding of the read are improving in the students of the fourth grade, but the understanding of the read is below the international standard of $80 \%$ correctly answered questions about the text. The statistical analyses showed that the two main factors for successful reading in all languages of instruction in both grades are developed reading skills prior to school enrollment and the availability of books at home. Students who have more books at their home also have better skills for understanding of the read. Greater involvement of the parents, the availability of more books and other reading materials, as well as the popularization of the libraries can contribute to improvement of the reading skills. Any intervention in the field of reading should be directed towards the students of satellite schools, students who have not enrolled in preschool institutions and the children whose parents have only primary education or no education at all"(Delčeva 2003, 89).

The Step by step research clearly shows that the results are unsatisfactory and they do not meet the international standards. In view of the above we can say with certainty that these bad results of the children in relation to the logical reading are a consequence of the defective program layout for Macedonian language teaching and the inadequate didactical-methodic position. There are undergoing reforms which aim to surpass these inconsistencies. According to the new programs, it is provided that the child in first grade should only read globally, while in the second grade the process of literacy trough the analyticallysynthetic voice method with global reading elements begins.

At some point, the integration of global reading into the curriculum was highly misunderstood. The main (and maybe the only) ob- jection is that our language (Macedonian) that has a phonetic orthography is not impressionable for this method that comes from Western European countries where the languages generally have etymological orthography. The main goal of this paper is to show that this objection is not valid. In the first part of the paper we are going to give three different perspectives on one problem: the relation of the part to the whole. In the second part we are going to define global reading and contextualize it in the frame of the part - whole problem: the education of the children substantially depends on the answers we are going to give on this questions. The relation of the letter to the word and of the word to the sentence is just concrete manifestation of this general problem.

\section{THE RELATION OF THE PART TO THE WHOLE 2.1. Kant, Cassirer and the
transcendental philosophy}

Philosopher Emanuel Kant's Copernican revolution conducted in The Critique of Pure Reason has set the building blocks of modern epistemology and psychology. We can say a lot about the discoveries that came out of this book, but we are interested in something concrete. Kant considered that the mind is the one that gives shape to the world. We cannot say anything about the world except that it is "a thing in itself". In Kant's philosophy the world and the mind are exchanging their places; the mind is primary, active and constructive, and the world is secondary, passive and constructed. The transcendentally of the mind is the one that constructs the world in "synthesis of apperceptions", and always as a coherent image in which the whole precedes the parts. That means that the perception, the experience and the interpretation are essentially inseparable. Every perception is a simultaneous organization and interpretation of the sensory experience. For example, the house is not perceived as a collection of windows, doors, walls and a chimney, but rather as a house in its entirety or as a totality that can later be disassembled to its basic elements. In Kant's opinion, in the primary act of perception, the parts are subservient to the concept which organizes them- in this case, the concept of the house (Kant 2012).

Cassirer recognizes Kant's discoveries, he upgrades and expands them. That which Kant made for the mind, Cassirer is making 
for the entire culture through adding the concept of symbol. He thinks that our entire experience is perceived through this mediative concept. We do not have any direct experience to the world itself, but the objects of the world are always perceived through the different symbols which they replace. Eco's defines the symbol quite clearly as "everything that, on the grounds of a previously established social convention, can be taken as something standing for something else" (Eco 1976, 15). The Biffurcation symbol-object is false and impossible, because the symbol is a necessary prerequisite for every experience (Cassirer 1961, 82 ). The culture, to Cassirer is a manifestation of different symbolic forms that shape our experience (language, myth, science, art etc.), and the criticism of the mind must be transformed into criticism of the culture.

It is especially important that Cassirer accepts Kant's premise about the predominance of the whole over the part. The news is that "the whole" in his theory is the culture itself as a system of symbols. In this part of the introduction from The philosophy of symbolic forms it is clearly specified that: "Thus the particular can be posited only on the basis of a universal schema which is merely filled with new concrete content as our experience of the thing and its attributes progresses... "All these relations disclose the same fundamental characteristic of consciousness, namely that the whole is not obtained from its parts, but that every notion of a part already encompasses the notion of the whole, not as to content, but as to general structure and form. Every particular belongs from the outset to a definite complex an in itself expresses the rule of this complex" (Cassirer 1980, 102). Culture is the one that synthesizes and shapes the flying pieces of our experience.

\subsection{Emile Benveniste and the primacy of the sentence}

Emile Benveniste, maybe the most appreciable heir of Ferdinand De Saussure, the father of structural linguistics, in 1964 publishes the essay The Levels of Linguistic Anal$y$ sis in which he gave interesting and important remarks on the nature of language and its connection with signification and meaning.

He thinks that the sign (the word) is a middle category that can be decomposed into lower constitutive units, in this case the phoneme and the merism, but at the same time that it can be integrated into the highest lin- guistic form - the sentence. When a linguistic unit is being decomposed, it is actually being reduced to its formal elements. This process of reduction made a lot of linguists think, that they could completely disregard the notion of meaning in language, and to replace it with mathematical formulae, that reduce the functioning of language on the possible combinations of its formal elements. This labor, according to Benveniste is Sisyphean, because meaning has central relevance on every level of the functioning of language. "In relation to the unit of the written word, the letters that compose it, taken one by one, are only material segments that do not retain any portion of the units. If we compose SATURDAY by assembling eight blocks, each of which bears a letter, the T block, the A block, etc., will not constitute an eighth or any other fraction of the word as such" (Benveniste 1971, 107).

When the word enters into the sentence and enters a higher level on the linguistic hierarchical structure, it undergoes a substantial transformation; it undergoes a transition from quantity to quality, said in Hegelian terms. The sentence, as defined by Benveniste does not depend on the length: the sentence can be composed of only one word. The context of its utterance is the thing that is essential. That means that the sentence is in the domain of the discourse. Benveniste's defines discourse like this: „Discourse must be understood in its widest sense: every utterance assuming a speaker and a hearer, and in the speaker, the intention of influencing the other in some way" (Benveniste 1971, 209). By abandoning the domain of language as a system it enters the domain of language as an instrument of communication. When language is observed as a discourse, it takes its intuitive form as an organic totality of interdependent elements that is directed to communication and the production of meaning. The abstract analysis of its formal elements is abandoned.

The consequences of Benvenistes are more than obvious. Once again, we reach the same conclusion that the whole necessarily precedes the part. Every constitutive unit of language, from the lowest merism, to the phoneme and the sign get their its function and meaning only in the context of the sentence. The sentence in this purport would have the meaning of discourse or context. Primarily every word has the function of communicating information and meaning, and the meaning is inseparably connected to the context in which it is used. 


\subsection{Jerome Bruner and the cultural premise of psychology and pedagogy}

The American psychologist Jerome Bruner is one of the pioneers of the cognitive revolution in psychology derived as a response to behaviorism, and also one of the first who imports the concepts of meaning and signification in the science of psychology. As Bogdanova writes, he is part of the second stage of the development of cognitive sciences together with Neisser, Lakoff and Johnson, that brings back the science to the subject (Bogdanova 2017, 146). Especially in his work Acts of Meaning he talks about "the nature and cultural shaping of meaning making" (Bruner 1990, XII), and the necessity of psychology becoming a "cultural psychology" and it's gaining an interdisciplinary boost from philosophy, semiotics, linguistics and etc.

In this paper we are especially interested in how this paradigm shift reflects on his educational theories. He, thinks, same as Cassirer, that culture is one broad outline, a story (he also talks about the narative nature of culture) that shapes the minds of the people participating in it. The mind cannot and should not be observed as an isolated entity that develops on the basis of its own biological conditioning. On the contrary, the mind has to be taken as „only“ an element in the complex matrix of intertwined meanings, or in other words, as a part of culture. Bruner talks against the „computer perspective" inspired from the thoery of informations, that is interested in the processing of informations that come into the mind. He opposes to (or upgrades) this point of view with the ,culturalist perspective“ in which the mind is not observed as machine, or a complicated algorithm, but as an interpreator of meaning - the mind is compered to the reader of a novel: "It leads us directly to the other approach to the nature of the mind - we can call it culturalist. That approach is inspired by the evolutionary fact that the mind cannot exist outside of culture"..."Culture in this sense is superorganic. Its individual expression is manifested by creation of meaning, by giving meaning to things in different environments and different situations..." Although the meaning is "in the head" its roots and its importance come from the culture that creates them" (Bruner 2000, 19).

This culturalist approach to the nature of the mind, necessarily leads to essential changes in the approach to the education of children: "The pedagogical implications of the mentioned are more than obvious. Taking concern for the limitations that are deeply seated in our mental predispositions that can be outstripped by imbibing influential symbolical systems, one of the tasks of education is to equip people with the required symbolical systems" (Bruner, 2000, 33). If every mind exists in a complex matrix of different symbolic forms, that the main task of education is to perform that symbol acquiring initiation.

Also, as the perspective to the mind is radically widened, the perspective to the education is going to have a wider scale: "Culturalism, for its first premise takes the fact that the education is not an island but a part of the continent of culture (Cassirer 1980, 102). As symbols are always part of the wider context of culture, and education's main preoccupation are symbols, than education must be about culture. That means that every educational goal has to be in correlation with the broader system of culture. The school does not exist in an isolated void, but as a part of culture. Once more, we can see, but this time from a different perspective that the part is necessarily subordinated to the whole.

\section{WHAT IS GLOBAL READING?}

The learning of primary literacy in the mother tongue by the method global reading does not take the letter as a primary basis for education, but instead takes the word. Every analysis and synthesis are being thrown off as redundant. Global reading is a method by which students learn to identify and to recognize the whole word before they are introduced to its formal elements, the letters by which it is composed.

Global reading is one of the more advanced and recent educational methods. Its emergence can be seen as a symptom of very concrete factors. In this chapter we are going to explain the method of global reading through its roots and genesis. The causes of the appearance of global reading can say a lot more about its essence.

The first of these factors is the place of "the birth" of this method. It comes from English and French, languages that have etymological orthography, and in which synthetic methods are inapplicable. Also, the analytic - synthetic method needs a complementary tool that will prepare the students for its later application.

This is the main target for critics to attack about the implementation of the global method in the Macedonian curriculum - the 
fact that the orthography of the Macedonian language is phonetical. The global method is observed as a foreign product that is not applicable to the specificities of the Macedonian language. We cannot argue with the fact that the method of global reading has a local origin, but that does not mean that the local context is the only reason for its implementation as a relevant educational method. That is a typical logical fallacy. Also, the local context does not restrain the possibility of its being used in a different context, certainly with a previous careful adjustment. The following three factors are going to confirm this argument.

The second factor is the changed living conditions, in which the children are exposed to intensive sensations and are gaining notions and presentations that were previously an exclusive property of the school. The subjection to varied commercials, newspapers, television, internet, posters, picture books, i.e. in the many different forms in which the culture manifests itself, it awakens an interest for reading in the children and it allows them to learn how to read spontaneously and unobtrusively in the preschool period. It should be noted that this primary literacy is not a result of studying letters but from recognizing entire words (globally) in the appropriate context in which they are observed and used. The simple examples from everyday life show that this is possible: if different newspapers and magazines are present in a household, the daily encounter with them leads to remembering the entire title. So, if the parent asks for a specific newspaper, with a specific name (for example, one time to ask for The Guardian and the second time for National Geographic the child will complete the task correctly and without a problem - ergo, the child reads. The child also recognizes the TV titles i.e. are distinguishing between his favorite cartoon, the interesting movie or the boring news broadcast. The situation is similar with the personal computer, where the child recognizes the tools with no problem and knows exactly how to use them, without knowing the letters. We can also add that the results from a recent research show that the use of computers have a positive effect on the creativity of children (Stošić, Stošić 2014).

All this implies that the child is already reading, not synthetically or analytically, but by recognition, globally. It is introduced in the language from the youngest age by the parents, a fact that psychologists and psychoanalysts point out as especially important in relation to the crossing of the child in a more complex sphere of existence - the sphere of symbols and culture (Smith 2001, 202-2014). The child's entry into the culture and symbolization means an entry into a new world which is fulfilled with sense and meaning, "Man is an animal suspended in webs of significance that he himself has spun". (Geertz 2007, 15), says the anthropologist Clifford Geertz in this semiotic definition of culture.

The method of global reading is in fact a method that is based on and adds up to this sui generis condition of the humanoid species as animal simbolicum (Kasirer 1998, 46) or homo significans (Barthes 1972, 218), i.e. its existence within culture: "Primary literacy by the global method requires the student to remember the word as a full optical image from which the sense (meaning) of that word arises directly, claim the global method supporters. Reading itself, represents a merging of the graphic image with the word, the speech... nonetheless the child learns to talk in full vocal forms, not by analysis and synthesis, which of course, must be taken into account when introducing the students to the process of reading" (Delčeva 2003, 89). Our argument is also in accordance with the psychological premise of the importance of visualization for children, a fact that is emphasized by the psychologists (Makarova, E. A. et al, 2017, 65-74).

That is the third factor that influenced the introduction of the method of global reading within the primary literacy-consciousness of humanities about the double nature of the man, as nature and as culture. Bruner's metaphor of education as an island from the continent of culture has proved correct, as a premise and as a confirmation of the global reading method.

The forth, and maybe the predominant factor which confirms the theoretical basis of this method is its respect for the knowledge of philosophers, psychologists and linguists about the predominance of the whole in relation to its constitutive parts.

\section{CONCLUSION}

The global reading method starts from the premise that the child exists in a web of relevancies in which it intuitively, through the very act of perception, understands and interprets. This method uses this advantage and integrates it in the curriculum; the basis that global reading gives, precedes the analyticalsynthetic method, which separates the already 
recognized whole to its components. The components cannot make sense outside of the whole in the context in which they are understood and used. We saw that through the theories of Kant, Cassirer, Benveniste, Bruner, and Geertz. Firstly, because of the nature of the mind as Kant points out, then by the complex intertwining of man, culture and symbolism as Cassirer, Geertz and Bruner showed, and lastly by the nature of language and meaning production in language as Benveniste illustrated. That's why global reading is an indispensable foundation for every process of primary literacy.

\section{Conflict of interests}

The authors declare no conflict of interest.

\section{REFERENCE}

Barthes, R. (1972). Critical Essays, Northwestern University Press, Evanston https://goo.gl/y2W8Hn

Benveniste, E. (1971). Problems in General Linguistics, University of Miami Press, Miami https:// edisciplinas.usp.br/pluginfile.php/294097/mod resource/content/1/Benveniste\%20(1).pdf

Bogdanova, M. A. (2017). Cognitive science: from multidisciplinarity to interdisciplinarity. International Journal of Cognitive Research in Science, Engineering and Education (IJCRSEE), 5(2), 145-150. https://doi.org/10.5937/ IJCRSEE1702145B

Bruner, J. (1990). Acts of Meaning, Harvard University Press, Massachusetts https://goo.gl/WNt56h

Bruner, J. (2000). Kultura obrazovanja, [Culture of Education]. Educa, Zagreb

Cassirer, E. (1961). The Logic of the Humanities, Yale University Press, New Haven

Cassirer, E. (1980). The Philosophy of Symbolic Forms - Volume one: Language, Yale University Press, New Haven

Delceva, J. (2013). The Compatibility of School Programs with the Coursbooks for Macedonian Language in Grades 1 and 2, Education Between Tradition and Modernity, Faculty of Philosophy, Skopje

Delceva, J. (2003). Didaktika na jazičnoto podračje vo osnovnoto obrazovanie [Didactics in the language field in elementary education], Prosvetno delo, Skopje

Eco, U., (1976). A Theory of Semiotics, Indiana University Press, Bloomington https://goo.gl/UEZeDq

Fondacija za obrazovni i kulturni inicijativi: Čekor po čekor [Step by step], Godišen izveštaj: 2016, www.Stepbystep.org.mk, http://www.stepbystep.org.mk/mk/1

Geertz, K. (2007). Tolkuvanje na kulturite [Tolerance on cultures], Magor, Skopje

Kant, I. (2012). Kritika čistoga uma [A critique of a pure mind], Dereta, Beograd

Kasirer, E., (1998), Esej za čovekot, [Essay for the man]. Kultura, Skopje

Makarova, E. A., Makarova, E. L., \& Varaksa, A. M. (2017). Education process visualization in metacognition development and sustainability. International Journal of Cognitive Research in Science, Engineering and Education (IJCRSEE), 5(2), 65-74. https://doi.org/10.5937/ IJCRSEE1702065A

Smith, P., (2001). Cultural Theory: An Introduction, Blackwell Publishing, Malden https://goo. $\mathrm{gl} / 8 \mathrm{rSZXi}$

Stošić, L., Stošić, I., (2014). Impact of Computers on the Creativity of Children, International Journal of Cognitive Research in Science, Engineering and Education 2 (2), 29 - 34, http://ijcrsee.com/ index.php/IJCRSEE/article/view/80 